\title{
Models for orbital debris and its optional solutions
}

\author{
Yuwei Ni, Jiahui Bi, Yilin Hou \\ Beijing Forestry University, athematics and Applied Mathematics, Beijing 100083, China \\ aemail: lylglg@163.com, bemail:kli20112012@163.com
}

Keywords: Orbital debris; Factor analysis; Grey Forecasting Model

\begin{abstract}
The problem of the total number of orbit debris in the future has been the center of public attention for a long time. On the basis of statistics data and accurate calculation, the paper builds models and set up a model system. Then combine reality and define six possible factors affect the volume of space junk. Using correlation analysis, the experiment determines the final four key factors: the annual number of failure of spacecraft launch, the number of annual retired spacecraft which will be junk, the amount of collision arising from avalanche effect, junk self-consumption. In the basis of this analysis, establishing Gray Forecast Model to predict the annual number of space junk in the next two centuries and find that there will be a substantial junk increase in the predictable future.
\end{abstract}

\section{Introduction}

Large quantities of former orbitals debris based on analysis and research indicate that the increasing of debris output is influenced by many different factors. In order to predict the number of orbitals debris in the future better, using factor analysis which will show how each factor has impact on the growth increments. After analyzing, the experiment chooses four main factors as impact factors to do factor analysis for debris output in space. Then, we do the relational grade analysis to compute the influence degree of every factor so that the predictive value of debris output in 200 years can be more veracious.

After evaluating the degree of the impact, the experiment eliminates unnecessary factors and end up with using four main factors as the impact factors. Then, it request to do relational grade analysis on the factors to quantize the influence so that the experiment can explore the origin and predict the total number of orbital debris better. At last, the experiment uses grey system theory to establish Grey Forecasting Model and get predictive value of orbital debris in 200 years because it is said that the number of debris will reach the critical point and maintain stability.

\section{Design of the Orbital Debris Mechanics}

By analyzing the source of orbitals debris in the last 20 years, we summarize six main factors which may affect debris output mostly as wrecks of spacecraft, discarded quantity of spacecraft, avalanche effect, self-depletion, astronauts' garbage as well as celestial remains. Then, we do special analysis for every possible factor.

\section{Wrecks of spacecraft D1}

We can obtain the data which is involved the status of spacecraft launch by different countries in 2012 from former data [1]. The status contain two part, which one is the number of failure times in 2012 and the other one is the total number of spacecraft launch. Integrating, we get the failure rate, where

$$
\mathrm{F}=\frac{\mathrm{FT}}{\mathrm{LT}}
$$

Here F donates the failure rate; FT donates the failure times and LT donates the lunch rate.

Meanwhile, combining the failure times in Table1 with the total number in Table1, we have the weights, which measure the country's influence in wrecks of spacecraft, to be

$$
\text { Weight }=\frac{\mathrm{LT}}{\sum \mathrm{LT}}
$$


Table. 1 Total number of space launch in the world

\begin{tabular}{cccccccccccc}
\hline Year & 2006 & 2007 & 2008 & 2009 & 2010 & 2011 & 2012 & 2013 & 2014 & 2015 & Total \\
\hline $\begin{array}{c}\text { Total } \\
\text { number }\end{array}$ & 305 & 346 & 208 & 246 & 91 & 68 & 66 & 53 & 40 & 27 & 1450 \\
\hline
\end{tabular}

Putting these together, we get the weighted average $\mathrm{x}$ :

$$
\bar{x}=\frac{x_{1} f_{1}+x_{2} f_{2}+\cdots+x_{k} f_{k}}{n}
$$

Which means the failure rate in 2012 all over the world, and the result is 0.0551 . Therefore, from the results above, we have D1 by using an approximate value as the failure rate to compute in Table2.

$$
\mathrm{D} 1=\overline{\mathrm{x}} * \sum \mathrm{FT}
$$

\begin{tabular}{cccccccccccc}
\hline Year & 2006 & 2007 & 2008 & 2009 & 2010 & 2011 & 2012 & 2013 & 2014 & 2015 & Total \\
\hline D1 & 16.81 & 19.06 & 11.46 & 13.55 & 5.01 & 3.75 & 3.64 & 2.92 & 2.204 & 1.49 & 79.90 \\
\hline
\end{tabular}

Table 2 shows the total wrecks of spacecraft which influences the amount of orbitals debris markedly.

Discarded quantity of spacecraft D2.

In fact, various products have been eliminated with perfect performance because of the end of their technical life span. Those massive discarded spacecraft will become a large apart of debris in space for no solutions to clean up themselves. So, we establish the second important factor as D2 which means the discarded quantity of spacecraft per year.

$$
\mathrm{D} 2=\mathrm{TP} * \mathrm{DR}
$$

Where TP denotes the total spacecraft per year and DR denotes the discarded ratio per year.

\section{Avalanche effect [4] D3.}

The phenomenon that orbital debris will rapidly grow since the collusion between debris or between spacecraft and debris is avalanche effect [2]. There is no doubt that the collision will produce a main part of debris so we take the collision into consideration as the third factorD3.

$$
\mathrm{D} 3=\mathrm{E} * \mathrm{P}
$$

Where E denotes the Total number of existing orbital debris, $\mathrm{P}$ denotes the collision probability.

According to the calculation result in the former literature [3], the collision probability in space is $10^{-4}$.

\section{Self-depletion D4.}

Actually, if the orbital altitude is high, the debris will preserve for a long time. However, the LEO debris will fall frequently because of the atmospheric drag, and it will burn out in the duration of returning. The self-depletion of debris is the fourth main factor which actually has a negative impact on output. In the same time, the different altitude of orbit, the different loss speed. What we can get is the probability of self-depletion [4], which is $17.72 \%$ in near-earth space and is $1.772 \%$ at all.

\section{Astronauts' garbage D5.}

According to statistics [5], since the first astronaut arrived in space, the number of astronauts' garbage has reached one hundred thousand because of accidents. There is no doubt that the accidental garbage will become a part of the orbital debris.

\section{Celestial remains D6.}

Though it is no so common, but the celestial remains [6] will be on the orbit due to the gravity and become a small part of the debris. So we take the celestial remains as one of factor in our model as D6. 


\section{Test results}

In table5, we summarize the number or debris per year. For each year, the number of debris is computed. Then, we delete two factors (D5, D6) for the low impact on the number of debris and the factors, so the result is represented as follow:

Table. 3 Numbers of debris and the factors

\begin{tabular}{ccccccccccc}
\hline Year & 2006 & 2007 & 2008 & 2009 & 2010 & 2011 & 2012 & 2013 & 2014 & 2015 \\
\hline Debris & 7313 & 11196 & 11894 & 13914 & 13951 & 14016 & 13633 & 13485 & 13179 & 13111 \\
D1 & 16.81 & 19.06 & 11.46 & 13.55 & 5.01 & 3.75 & 3.64 & 2.92 & 2.2 & 1.49 \\
D2 & 32.43 & 33.03 & 33.644 & 33.667 & 34.10 & 34.96 & 36.36 & 38.119 & 40.30 & 41.29 \\
D3 & 1.03 & 1.424 & 1.499 & 1.705 & 1.709 & 1.724 & 1.698 & 1.700 & 1.689 & 1.691 \\
D4 & 129.59 & 198.39 & 210.76 & 246.56 & 247.21 & 248.36 & 241.58 & 238.95 & 233.53 & 232.33 \\
\hline
\end{tabular}

Then we do the correlation degree [7] among the different relevancy, the result is as follows:

Table.4 Correlation degree between space debris and factors

\begin{tabular}{ccccc}
\hline Factor & D1 & D2 & D3 & D4 \\
\hline Relevancy & 0.717 & 0.694 & 0.704 & -0.693 \\
\hline
\end{tabular}

We can learn that wrecks of spacecraft (D1) have the highest correlation degree, which means the influence of increasing wrecks is remarkable. And the discarded quantity of spacecraft (D2) as well as avalanche effect (D3) has close relationship with the growth of debris, while self-depletion (D4) decreases the amount of debris.

\section{Grey Forecasting Model for orbitals debris}

Based on the factor analysis on Model 1, we implement our Model2 successfully via MATLAB7.0. Since 2015, it remains 200 years to reach the critical value of orbital debris and maintain stability without disturbances. So we choose the data from 2006 to 2015 about the total of orbital debris and use Grey Forecasting Model GM $(1,1)$ to forecast its total quantity in 200 years in the future.

The Grey System [8] mainly works on a system analysis which has produced poor, incomplete or uncertain messages. The advantages of the Grey Model are it can use only a few data to estimate an unknown system, and it can use a first-order differential equation to characterize the unknown system's behavior.

Given the original data set:

$\mathrm{x}^{(0)}=\left(\mathrm{x}^{(0)}(1), \mathrm{x}^{(0)}(2), \ldots \ldots \mathrm{x}^{(0)}(10)\right)$

Where $\mathrm{x} 0$ (i) correspond to the system output from 2006 to 2015

A new sequence called AGO is generated:

$\mathrm{X}^{(1)}=\left(\mathrm{x}^{(1)}(1), \mathrm{x}^{(1)}(2) \ldots \ldots, \mathrm{X}^{(1)}(10)\right)$

Where

$\mathrm{x}^{(1)}(\mathrm{k})=\sum_{\mathrm{i}=0}^{\mathrm{k}} \mathrm{x}^{(0)}(\mathrm{i}),(\mathrm{k}=1,2, \ldots \ldots .10)$

So we can have the grey derivative:

Solve the different equation

$\frac{\mathrm{dx}^{(1)}}{\mathrm{dt}}+\mathrm{ax}^{(1)}(\mathrm{t})=\mathrm{b}$

And obtain the expression

$\mathrm{x}^{(1)}(\mathrm{k}+1)=\left(\mathrm{x}^{(0)}(1)-\frac{\mathrm{b}}{\mathrm{a}}\right) \mathrm{e}^{-\mathrm{ak}}+\frac{\mathrm{b}}{\mathrm{a}}, \mathrm{k}=1,2, \cdots, \mathrm{n}-$

Then, the nearest- neighbor mean sequence is 
$\mathrm{Z}^{(1)}(\mathrm{k})=0.5 \mathrm{x}^{(1)}(\mathrm{k})+0.5 \mathrm{x}^{(1)}(\mathrm{k}-1), \quad \mathrm{k}=2,3, \ldots \ldots .1$

Where

$\mathrm{z}^{(1)}=\left(\mathrm{z}^{(1)}(2), \mathrm{z}^{(1)}(3), \ldots \ldots, \mathrm{z}^{(1)}(10)\right)$

From $x(1)$, we can form the first-order differential equation: $d^{(k)}+a x(1)(k)=u$

From which it is possible to obtain a and $\mathrm{u}$ with

$\mathrm{u}=(\mathrm{a}, \mathrm{b})^{\mathrm{T}}, \mathrm{B}=\left[\begin{array}{cc}-\mathrm{z}^{(1)}(2) & 1 \\ -\mathrm{z}^{(1)}(3) & 1 \\ \vdots & \vdots \\ -\mathrm{z}^{(1)}(\mathrm{n}) & 1\end{array}\right]$

And

$\mathrm{Y}=\left(\mathrm{x}^{(0)}(2),\left(\mathrm{x}^{(0)}(3), \cdots,\left(\mathrm{x}^{(0)}(\mathrm{n})\right)^{\mathrm{T}}\right.\right.$,

So, we can get

$\hat{\mathrm{u}}=(\hat{\mathrm{a}}, \hat{\mathrm{b}})^{\mathrm{T}}=\left(\mathrm{B}^{\mathrm{T}} \mathrm{B}\right)^{-1} \mathrm{~B}^{\mathrm{T}} \mathrm{Y}$

And obtain the expression

$\mathrm{x}^{(1)}(\mathrm{k}+1)=\left(\mathrm{x}^{(0)}(1)-\frac{\mathrm{b}}{\mathrm{a}}\right) \mathrm{e}^{-\mathrm{ak}}+\frac{\mathrm{b}}{\mathrm{a}}, \mathrm{k}=1,2, \cdots, \mathrm{n}-1$

Establish the model based on what said above, and get the fitted and predicted series by using the least square method. That is

$$
\hat{\mathrm{x}}^{(1)}(\mathrm{k}+1)=\left(\mathrm{x}^{(0)}(1)-\frac{\mathrm{b}}{\mathrm{a}}\right) \mathrm{e}^{-\mathrm{ak}}+\frac{\mathrm{b}}{\mathrm{a}}, \mathrm{k}=1,2, \cdots, \mathrm{n}-1 \text {. }
$$

We determine absolute and relative values for wrecks from 2006 to 2015 for which all the date used in computing parameters is available. Then, we take an exact test for Grey Model by comparing the actual values to the simulate values from 2006 to 2015 on number of debris. We choose relative error (q), variance ratio(c) as well as probable error (p) as three indexes for the test. The results via MATLAB7.0 and the grade of it are in Table5.

Table.5 Relative error, variance ratio and probable error [9]

\begin{tabular}{cccc}
\hline Grade & $\begin{array}{c}\text { Relative } \\
\text { error(q) }\end{array}$ & $\begin{array}{c}\text { Variance } \\
\text { ratio(c) }\end{array}$ & $\begin{array}{c}\text { Probable } \\
\text { error (p) }\end{array}$ \\
\hline Grade- I & $<0.01$ & $<0.35$ & $>0.95$ \\
Grade II & $<0.05$ & $<0.50$ & $<0.80$ \\
Grade- II & $<0.10$ & $<0.65$ & $<0.70$ \\
Grade-IV & $>0.20$ & $>0.80$ & $<0.60$ \\
Result & 0.0038 & 0.1495 & 1 \\
\hline
\end{tabular}

Table. 5 shows exact test for Grey Model on our dates. It turns out that the accuracy of our model is high level for relative error(q),variance ratio(C) as well as probable error(p) are the I grade, which means this model close to reality and can be used to predict the quantitative change of wrecks in space in the future.

\section{Model prediction}

According to the former statistic values, it remains 200 years to reach the critical point and maintain stability. So, using the Grey Model via Matlab7.0, we forecast the number of debris in 200 years. Because of the enormous data, we choose a part of the result and present them in Table. 6 .

Table. 6 Forecast values for debris

\begin{tabular}{cccccccccccc}
\hline Year & 2016 & 2017 & 2018 & 2019 & 2020 & 2021 & 2022 & 2023 & 2024 & 2025 & 2026 \\
\hline $\begin{array}{c}\text { Forecast } \\
\text { Debris }\end{array}$ & 13990 & 14170 & 14350 & 14530 & 14710 & 14900 & 15080 & 15270 & 15470 & 15660 & 15860 \\
\hline
\end{tabular}




\section{Conclusion}

The test has used mathematical model to analyze the current status and the future trend of orbital debris in future. It's clear that the total of debris will continuous increase and reaches to $10 \times 105$ in 2210. In foreseeable future, the amount of orbital debris will become a serious threat to our explosion in space.

\section{References}

[1]http://wenku.baidu.com/link?url=8FSV1fegD-9oiWmnI7HvrX5fDP3-JiqlqvOYyBYJPmMiaNS yM0HBDDkv8u8hdvghF5GWVPQyGUdhiScOJzeKUzbESTERxD_Gh_8gtKa5mZC

[2] http://world.people.com.cn/n/2014/0415/c1002-24897436.html

[3] Xia Fuan. “Space trash” harm and control [J]. Aviation knowledge, 1999(6):44-44.

[4] Secret genius. There is rubbish in space.[J]. Scientific enlightenment,2015(5). Space debris early warning

[5] Wang Yan, Dong Yunfeng, Han Chao. Space debris lifetime algorithm based on spacecraft breakup event [J]. Journal of Beijing University of Aeronautics and Astronautics, 2007, 33(11):1268-1272.

[6] Tang Libiao. Scientific assumption of N for cleaning up space junk [J], 2009(2).

[7] Cheng Fangming, Zhong Lianjin,. Variation of rice quality traits under different climatic and ecological conditions and its main influence factors [J]. Chinese Journal of Rice Science, 2001, 15(3):187-191.

[8] Lin Haiming, Zhang Wenlin,. Similarities and differences between principal component analysis and factor analysis and SPSS software [J]. Statistical research, 2005(3):65-69.

[9] http://lia.deis.unibo.it/research/SOMA/SmartBuffer/Client/htmlDocs/detailsMobPred.html

[10]Kumar U, Jain V K. Time series models (Grey-Markov, Grey Model with rolling mechanism and singular spectrum analysis) to forecast energy consumption in India[J]. Energy, 2010, 35(4):1709-1716. 